\title{
Patterns of intentional faking in questionnaire-based study of psychopathy
}

\author{
Jarosław Groth $^{A, B, D, E}$, Pawet Kleka ${ }^{C, D, E}$ \\ Institute of Psychology, Adam Mickiewicz University in Poznań, Poland
}

\section{BACKGROUND}

The aim of the study was to identify the patterns of two types of faking the results of a self-report study - faking good and faking bad - and to determine their relationships with the images obtained as a result of completing a questionnaire in accordance with the standard instructions and therefore regarded as subjectively true. We investigated faking resulting from a short-term attitude stemming from the presence of a particular theme in the context of the items of a questionnaire assessing psychopathic personality.

\section{PARTICIPANTS AND PROCEDURE}

The results were collected in a population of participants $(N=173)$ of full legal age and without a criminal record. To examine the research problem, we used cluster analysis and Pearson's $r$ correlation coefficient. Calculations were performed in the $\mathrm{R}$ environment. The division of participants into homogeneous groups was based on the criterion of optimal breadth of the Silhouette index in accordance with the Partitioning Around Medoids (PAM) method.
RESULTS

Five separate patterns of faking good and three patterns of faking bad during self-report assessment were distinguished. Intergroup differences in traits and behaviors characteristic of psychopathy in the groups distinguished based on the pattern of faking bad were not found.

\section{CONCLUSIONS}

It can be concluded that the levels of traits and behavior patterns defining psychopathic personality are related to a particular profile produced as a result of faking good. The present study does not show the existence of a relationship between the level of psychopathy and any particular strategy of presenting oneself in a worse light.

\section{KEY WORDS}

psychopathy; questionnaire-based study of personality; faking good, faking bad

CORRESPONDING AUthor - Jarosław Groth, Ph.D., Institute of Psychology, Adam Mickiewicz University in Poznań, 89 AB Szamarzewskiego Str., 60-568 Poznań, Poland, e-mail: groth@amu.edu.pl

Authors' Contribution - A: Study design · B: Data collection · C: Statistical analysis · D: Data interpretation .

E: Manuscript preparation · F: Literature search $\cdot$ G: Funds collection

TO CITE THIS ARTICLE - Groth, J., \& Kleka, P. (2018). Patterns of intentional faking in questionnaire-based study

of psychopathy. Current Issues in Personality Psychology, 6(4), 305-317.

RECEIVED 15.09.2017 · REVIEWED 29.01.2018 - ACCEPTED 13.09.2018 · PUBLISHED 19.11.2018 


\section{BACKGROUND}

Questionnaire-based study of personality relying on self-knowledge and self-report requires the subject's introspection - insight into their own mental states, into their ideas of the world and their own self - as well as the capacity and willingness to communicate honestly. Scholars differ in their evaluation of the quality of psychological assessment performed in this way. Although the usefulness of questionnaires in personality assessment is stressed - and in the case of psychopathic personality some even speak of their renaissance (Lilienfeld, 1998; Lilienfeld \& Fowler, 2006) - assessment specialists unanimously agree that questionnaires are prone to distortions (Goffin \& Boyd, 2009; Goffin \& Christiansen, 2003; McFarland \& Ryan, 2006; Zickar \& Robie, 1999). Some of the errors, such as those stemming from a permanent tendency to exhibit centrality or lateralization, or to give only positive or only negative answers - considered in terms of individual response style (Brzezińska \& Brzeziński, 2011; Paulhus, 2002) - depend neither on the contents of the questionnaire's items nor on the circumstances of the study ${ }^{1}$. Others are associated with the interaction of item contents and the circumstances of the study and stem from intentional or unintentional aspirations of the subject, striving to achieve a goal.

In the latter case (faking), it is possible to encounter an attitude of deliberately sabotaging the results by giving random or nonsensical answers and a practice of distorting "the truth about oneself" by choosing the answers that, in the subject's opinion, attest to good social adjustment and are socially desirable. Errors of this kind are diverse (Paulhus, 1984, 2002). Strategies of deception in self-report can be defined as "faking good" and "faking bad" response sets. In the latter case, distortion consists in lying or in exaggerating physical or psychological symptoms in order to achieve an external goal (Eitan, 2011).

Some respondents present themselves inaccurately as a result of limited insight into and understanding of themselves. They focus on the social value of the content presented in the item and use tactics that are expected to provide social approval or give a sense of self-image integrity, while in fact deceiving themselves and believing in the truthfulness of the self-report thus articulated (self-deceptive enhancement, self-deceptive denial; Paulhus, 1998; Paulhus \& Holden, 2009; Paulhus \& Reid, 1991). Regardless of whether the participants adopt a defensive attitude, presenting themselves in a better light, or an excessively critical attitude, attributing faults to themselves (Sanocki, 1970), the presented picture is subjectively true.

Sometimes, however, participants try to use the social value of the questionnaire's items instrumentally and consciously fake the result in order to influence other people's decisions. To make an impression on the audience, they consciously manage their image (impression management) and try to obtain a particular profile: generally positive, presenting them in a favorable light (faking good, dissimulation), positive in a given context (e.g., in a particular professional role) (Furnham, 1990; Jackson \& Wroblewski, 2000; Sanocki, 1978, p. 247), or negative (faking bad, simulation).

The value of the assessment of a given variable by means of a personality questionnaire is a function of the degree to which the subject decides to honestly disclose its indicators - hence the charge of proneness to intentional faking, often leveled against instruments of this kind (Furnham 1986). The examined person realizes the importance of the result in the context of his or her life plans. It can therefore be expected that the picture presented during the examination performs instrumental functions with regard to the person's goals (Arendasy, Sommer, Herle, Schützhofer, \& Inwanschitz, 2011; Paluchowski, 2001, p. 86). This is particularly important in the case of tests measuring psychopathy, usually administered in situations in which the assessment of an individual's condition and the decisions based on it may determine the person's fate, thus inducing him or her to engage in self-presentation.

Models explaining the process of faking comprise two distinct components, dependent on personality and contextual factors and influencing the distortion of results: the individual's motivation and ability (or "perceived ability") to fake answers (McFarland \& Ryan, 2000, 2006; Snell, Sydell, \& Lueke, 1999). Motivation to fake answers is a product of personality traits, moral norms, attitude towards cheating, perceived behavioral control, perceived negative consequences of deception, perceived need to fake answers, the awareness of the existence of a validity scale, etc. Perceived ability to fake answers depends on personality traits, abilities and experience in the area of deception, perceived chance of perpetrating deception successfully, as well as on knowledge about the measured construct and about social expectations regarding the result (McFarland \& Ryan, 2000, 2006).

An example of a model that makes it possible to distinguish a set of personality traits fostering motivation to fake is the five-factor model (FFM). Goffin and Boyd (2009) suggest that individuals with high motivation to fake results are characterized by low sense of responsibility, low prudence, low depressiveness, low anxiety, and low hypersensitivity, as well as high ambition and striving for achievement and high impulsiveness. This configuration is supplemented by the individual morality component, associated with the expression of FFM traits (Siuta, 2006).

It has been proved that FFM dimensions make it possible to describe psychopathic personality, too (Groth \& Cierpiałkowska, 2012; Lynam \& Derefinko, 
2006; Mullins-Sweatt \& Widiger, 2006). According to expert researchers describing psychopathy in terms of NEO-PI-R components (Miller et al., 2001), the profile of a typical psychopath (Hare, 2003) is composed of low scores on dutifulness, self-discipline, deliberation, anxiety, depressiveness, hypersensitivity, or trust and high scores on impulsiveness, sensation seeking, and openness to actions. These results turned out to be consistent with those of other studies identifying the relationships between FFM traits and psychopathy (Lynam, 2002; Lynam \& Derefinko, 2006; Widiger \& Lynam, 2003). The coincidence of the traits distinguished by Goffin and Boyd (2009) with the above supports the thesis postulating the high motivation of psychopathic individuals to fake.

The tendency and ability of psychopathic individuals to engage in deception in interpersonal relationships, pathological lying, and manipulation is one of the distinctive features of their disorder. Several attributes of the prototypical image of a psychopath contribute to the development of this tendency (Cooke, Michie, \& Skeem, 2007; Hare, 2003; Hare et al., 1990; Hare \& Neumann, 2006).

The commonly accepted four-factor model of psychopathy reflects psychopathic individuals' typical attitude towards themselves and others as well as their chronically unstable and aimless lifestyle, characterized by unplanned and flagrant violations of social norms and expectations (Hare, 2006). Eloquence and superficial charm make it easier for a psychopath to make a favorable impression on the interlocutor, whom he or she volubly tells incredible though convincing stories presenting him or her in a favorable light. The motives behind lying and deception, either carefully premeditated or perpetrated on the spur of the moment, are diverse. Although manipulation may serve specific goals (financial gain, power, or success), it is often itself a source of satisfaction and pride in the ability to identify other people's weak points and the opportunities to deceive them. A dichotomous view of the world as consisting of "victims" and "predators" - which is promoted by unrealistic beliefs concerning one's own abilities and excessively high self-esteem - justifies attempts to control and take advantage of others without regard for the negative consequences of these actions. Such people easily rationalize the consequences of their actions, deny them, and externalize blame. Inability to take responsibility for one's own actions also stems from the lack of empathy, remorse, and a sense of guilt, which are accompanied by a superficiality of feelings and by emotional coldness. As a result of the sense of being privileged and having special authority, these people follow their own rules only and are prepared to violate norms. Perceiving themselves as forced to fight for their own rights, they are prepared to try to deceive the assessment specialist and to "beat" him of her in the examination situation.
The demystification of the fabricated stories does not evoke fear, embarrassment, or discomfort. When caught lying, a psychopath easily finds the necessary explanation or excuse and modifies the story to agree with the new facts. An issue worth mentioning is the tendency of psychopathic individuals to pseudoidentification, whose influence on the unintentional distortion of self-report test results seems not to have been investigated to date (Kosson, Gacono, \& Budholdt, 2000).

Psychopaths' tendency to manipulate and deceive is a phenomenon well known to assessment specialists; it argues against trusting the data obtained in interviews and in favor of confronting them with data from independent sources (APA, 2000, p. 702; Meloy \& Gacono, 2000; Reise \& Oliver, 1994; Rogers \& Cruise, 2000). Strategies of this kind are exemplified by the procedures of studies involving the Psychopathy Checklist-Revised (PCL-R) or the Antisocial Process Screening Device (APSD), where information obtained in interview is juxtaposed with other people's perspective and the available documentation.

To sum up, clinical observations and analyses of assessment processes show a high capacity of psychopathic individuals to engage in manipulation and to manage the presented image of themselves in situations of direct interpersonal contact (Cleckley, 1988; Hare, 2006; Klaver, Lee, \& Hart, 2007). Scholars investigating psychopathy stress the significance of high cognitive empathy capacity, allowing this kind of person to work out the assessment psychologist's reactions and expectations.

However, empirical studies confirming the relationships between the characteristics of psychopathy (Machiavellianism, ruthlessness, narcissism) and the capacity to fake the results of self-report tests (MacNeil \& Holden, 2006) do not yield conclusive findings. They rather suggest that Machiavellian abilities are conducive to successful deception in the real world and in an experimental context involving an interpersonal relationship. But this phenomenon relates to deception rather than to faking.

Phenomena connected with self-presentation are referred to by means of various terms: socially desirable responding, misrepresentation, faking, dissimulation, underreporting, defensiveness, malingering, misrepresentation, and overreporting of psychopathology. These phenomena are observed, above all, in interpersonal relationships, but they can be expected also in questionnaire-based studies.

Although the questionnaire-based method of personality assessment derives from structured clinical interviews and is their simplified version, in which the procedure has been streamlined in terms of time economy and the possibility of testing many people at the same time, the lack of interpersonal contact and the impossibility of verifying the responses 
based on the investigator's reactions observed by the person examined may deprive the psychopathic individual of the possibility of fully using his or her abilities of deceiving and faking.

As a result of the risk of deception in interpersonal relations in which psychopathic individuals are involved, the issue of measurement and psychological assessment of psychopathy is the focus among specialists in diagnosis and makes in-depth research necessary. The problem is particularly important due to the fact that, in the majority of cases, the main psychological instrument used to assess psychopathy is a questionnaire (SRP-II, SRP-E, PPI-R, etc.; Hare, 2008).

Views on the usefulness self-report instruments in the assessment of psychopathy are divided. Some scholars, referring to clinical observations, believe that these instruments should not be recommended as tools measuring psychopathy for clinical and research purposes (Hare, 1996, p. 29). Others, however, remain cautious in their judgments and point out the need to conduct further studies, stressing that the validity of questionnaires in research on psychopathy remains an open issue (Lilienfeld, 1998).

Although the results of some studies support the intuitively expected relationship between the tendency to deceive and psychopathy (Rogers \& Cruise, 2000; Seto, Khattar, Lalumiére, \& Quinsey, 1997), the associations between psychopathy and the ability to fake effectively when completing personality inventories have not been conclusively established. Nevertheless, it is worth mentioning certain studies that reveal differences manifesting themselves in the higher capacity of psychopathic individuals to deceive effectively.

According to research results, the capacity to fake effectively to suggest better adjustment in self-report personality questionnaires (i.e., to fake good) is, in fact, associated with a higher level of psychopathy as indicated by overall scores (Book, Holden, Starzyk, Wasylkiw, \& Edwards, 2006) or by scores on individual scales (MacNeil \& Holden, 2006). The results of the latter study, conducted by means of the PPI, showed that, although there were no differences in the overall level of psychopathy between individuals faking effectively and ineffectively, the respondents effective in faking good scored higher on Machiavellian egocentricity and blame externalization and lower on stress immunity. This study suggests the existence of components in psychopathy that foster effectiveness in faking good. The differences between the cited studies may stem from the use of different instruments. Similarly, the study by Edens et al. (2001) demonstrates that individuals with a high level of psychopathy are able to decrease their scores on self-reported psychopathy to a greater extent than individuals low in psychopathy.

Unlike in the case of research on the phenomenon of faking good, laboratory studies - often using the PPI questionnaire - prove that the capacity to fake bad in self-report personality questionnaires is not related to the characteristics of psychopathy (e.g., Book et al., 2006; Edens, Buffington, \& Tomicic, 2000; MacNeil \& Holden, 2006). Interestingly, the lack of high ability to fake disorder symptoms during the study was accompanied by their readiness and declared intention to distort the results.

The contrary findings in the literature of the subject, reporting strong relationships between psychopathy and simulation (Gacono, Meloy, Sheppard, Speth, \& Roske, 1995), stand in opposition to studies showing that effective faking tends to concern the phenomenon of faking good and revealing no relationship between psychopathic characteristics and faking bad effectively.

\section{THE PRESENT STUDY}

The aim of the study was to identify the patterns of two types of faking the results of a self-report study faking good and faking bad - and to determine their relationships with the images obtained as a result of completing a questionnaire in accordance with the standard instructions and therefore regarded as subjectively true. We investigated faking resulting from a short-term attitude stemming from the presence of a particular theme in the context of the items of a questionnaire assessing psychopathic personality.

We expected that, despite the instructions containing a request to answer honestly and despite the assurance of anonymity, there would be unintentional faking of questionnaire scores as a result of limited self-insight and self-understanding (this deficit is found in many psychopathic individuals), unintentional tactics of seeking social approval, or the need to maintain self-image integrity. We assumed that despite this kind of unintentional distortions (defensive or excessively critical) the presented image is perceived as subjectively true.

To assess the level and configuration of psychopathic traits as well as the images generated when giving deviant answers, we administered the Psychopathic Personality Inventory - Revised (PPI-R; Lilienfeld \& Widows, 2005). As a theoretically well-founded instrument characterized by acceptable reliability and validity, it is one of the most frequently used tests for the study of psychopathy in both criminal and noncriminal populations (Witt, Donnellan, \& Blonigen, 2009). Compared to items of other self-report measures, the items of this test refer to deviant behaviors to a smaller extent and to personality traits to a greater extent. As a result, it is assumed that the greater subtlety of the applied indicators of psychopathy makes untrue selfpresentation more difficult for the respondents.

The obtained personality profile comprises the scores on eight scales: Machiavellian egocentricity $(\mathrm{ME})$, Rebellious nonconformity $(\mathrm{RN})$, Blame externalization (BE), Carefree nonplanfulness $(\mathrm{CN})$, Social 
influence (SOI), Fearlessness (F), Stress immunity (STI), and Coldheartedness (C). The first four scales (ME, RN, BE, and CN) make up the Self-centered impulsivity factor (SCI), a further three (SOI, F, STI) make up a factor called Fearless dominance (FD), and the $\mathrm{C}$ scale measures the Coldheartedness factor (Neumann, Malterer, \& Newman, 2008).

The items of the questionnaire have the form of statements, which the subject is supposed to respond to by indicating the degree to which they reflect reality on a 4-point scale.

\section{PARTICIPANTS AND PROCEDURE}

\section{PARTICIPANTS}

The study was conducted on volunteers, and participation was anonymous. The respondents were recruited via opportunity sampling. The results were collected by three trained investigators in a population of participants of full legal age and without a criminal record. The sample was a group of 173 participants - 95 women and 78 men - aged 18 to 49 (mean age was $28 \pm 7$ years, with no gender differences, $p=.249)$. Higher $(56.00 \%)$ and secondary education $(38.00 \%)$ predominated in the sample. The largest proportion of the participants lived in big cities with a population of over $100,000(33.00 \%)$ and in villages $(31.00 \%)$, and a somewhat smaller proportion lived in towns with up to $25,000(23.00 \%)$ and up to 100,000 inhabitants $(13.00 \%)$. A large majority of the participants worked full-time $(62.00 \%)$ or ran their own businesses $(6.00 \%) ; 25.00 \%$ of the participants were students and $7.00 \%$ were unemployed.

\section{PROCEDURE}

The study was questionnaire-based - the participants were asked to complete the Psychopathic Personality Inventory (PPI-R) three times. The Psychopathic Personality Inventory was developed to detect psychopathic traits in noncriminal samples. PPI-R is the most widely used self-report measure of psychopathy. It consists of 154 items in a 4-point Likert-type format. The PPI yields a total score representing global psychopathy and eight subscales that assess lowerorder facets of psychopathy. This measure also contains validity scales intended to detect response styles that are potentially problematic among psychopaths: positive impression management, malingering, and careless or random responding. The first stage of the study was preceded by a request to complete the questionnaire honestly, in accordance with self-knowledge (in accordance with the standard instructions). Next, the participants were asked to fake the result in such a way as to produce profiles presenting themselves in a better and worse light, using the social value of the questionnaire's items instrumentally for that purpose. First, the participants were to distort the picture of "truth about themselves" by choosing the answers they believed to be socially desirable and to attest to good social adjustment (dissimulation, faking good). In the second stage of the study, the participants were to produce a distorted image of themselves by choosing the answers they believed to be socially undesirable (simulation, faking bad).

To examine the research problem, we used cluster analysis and Pearson's $r$ correlation coefficient. Calculations were performed in the $\mathrm{R}$ environment ( $\mathrm{R}$ Core Team, 2017). The division of participants into homogeneous groups was based on the criterion of optimal width of the Silhouette index in accordance with the Partitioning Around Medoids method (PAM; Reynolds, Richards, de la Iglesia, \& Rayward-Smith, 1992). Number of clusters was assessed based on the Duda-Hart test (1973).

\section{RESULTS}

The PPI-R has two control scales, whose purpose is to detect Virtuous responding (VR) and Deviant responding (DR). We found no significant relationship between the magnitude of change in the scores on specific scales measuring psychopathy and the scores on the control scales $(r<.30, p>.050)$; we did, however, find a relationship between the averaged magnitude of change (with its direction taken into account) for the Self-centered impulsivity factor and the scores on the control scales. In the case of positive pictures generated in response to the faking-good instruction, the correlation with VR was found to be significant $(r=-.39, p<.050)$, while in the case of the faking-bad instruction the magnitude of change correlated with DR $(r=.34, p<.050)$. The obtained results confirm the authors' suggestions (Lilienfeld \& Widows, 2005) that a high score on VR may attest to a deliberate attempt to manage the impression made and to present oneself as a person without personality problems (faking good), whereas a high DR score may attest to faking bad and to the simulation of symptoms of seemingly credible but in fact nonexistent mental disorders. With the increasing level of score aggregation and with the addition of successive scales, the picture of a given person's profile becomes blurred, thus limiting the possibility of identifying the manner of change. Especially when a part of the profile is increased and another part of it is decreased - nothing changes from the point of view of the overall result.

In order to examine the possible changes, we applied cluster analysis to identify profiles in particular groups of results. Using this method, we distinguished five clusters with different profiles of positive self-presentation $(F(4,1344)=113.9, p<.001)$ and 
Faking good

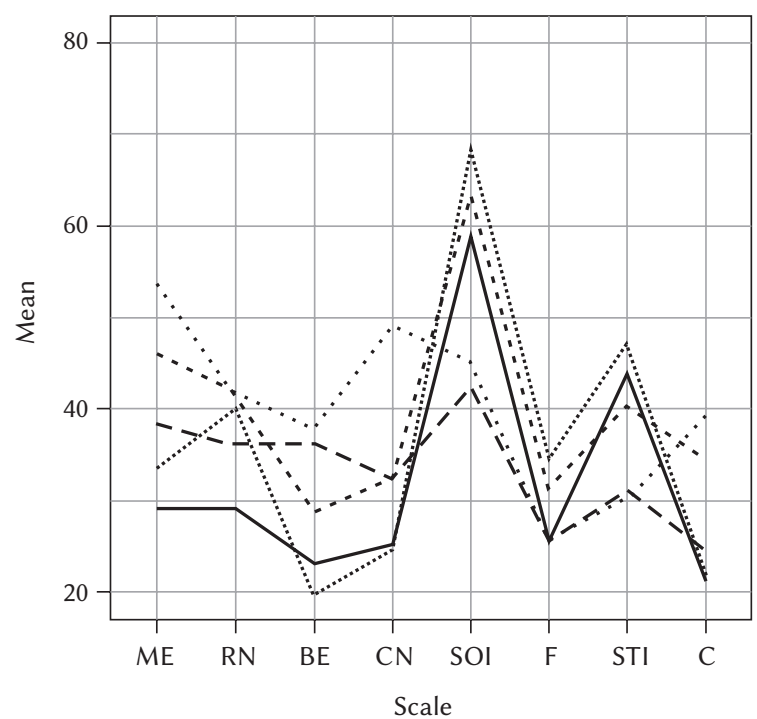

Faking bad

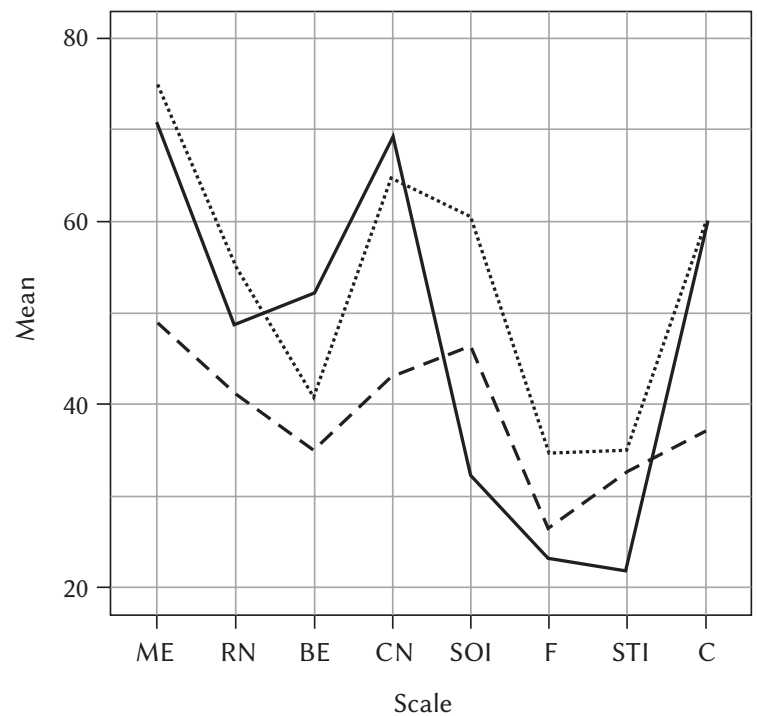

True profiles

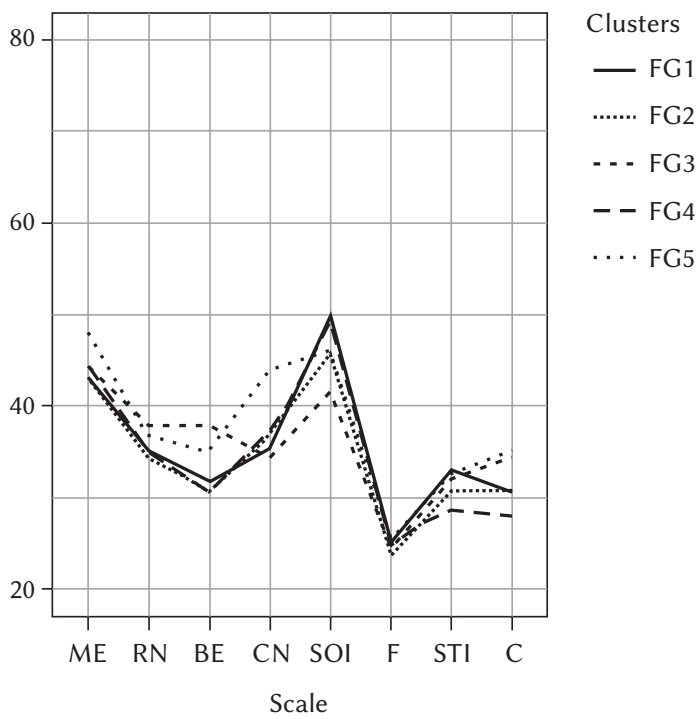

True profiles

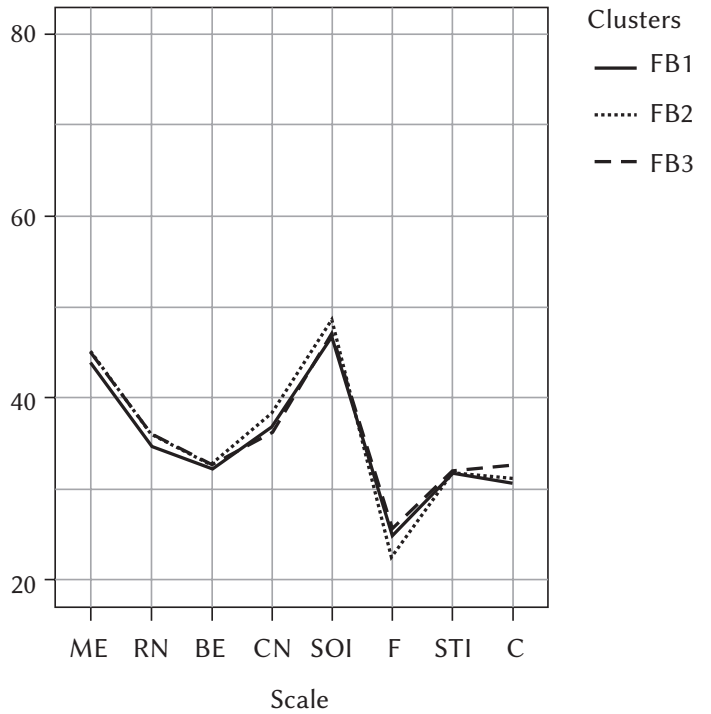

Note. ME - Machiavellian egocentricity; RN - rebellious nonconformity; BE - blame externalization; $\mathrm{CN}$ - carefree nonplanfulness; SOI - social influence; F - fearlessness; STI - stress immunity; C - coldheartedness; FG1, 2, 3, 4 - faking good, cluster 1, 2, 3, 4, 5 ; FB1, 2, 3 - faking bad, cluster 1, 2, 3.

Figure 1. Traits (the result of honest questionnaire completion) and images (distorted traits). The types of line indicate specific profiles.

three clusters differing in terms of the negative images presented $(F(2,1360)=315.5, p<.001)$. We found no differences in the number of women and men across the clusters $\left(\chi^{2}(10)=17.1, p=.070\right)$. In order to assess the type of faking, we juxtaposed faked profiles with subjectively true profiles of traits obtained in self-report preceded by the standard instruction (Figure 1).

The analysis of the groups of participants creating positive images (i.e., images resulting from faking good) in the case of the first four clusters revealed low differentiation in terms of traits and behavior patterns typical of psychopathy. The profile that was different from the others was the group of individ- uals whose pattern of intentional faking emerged as cluster FG5. This cluster consists of participants with a higher levels of psychopathic traits making up the factors of Self-Centered Impulsivity (ME, RN, BE, CN) and Coldheartedness (C) compared to the remaining groups and at the same time with the lowest level of Social influence (SOI). This group can be assumed to be the one with the most prominent psychopathic traits.

Although the participants turned out to differ in terms of the negative images of themselves they presented (faking bad), we did not find intergroup differences in the traits and behavior patterns typical of psy- 
True profile for people from cluster FG1 and changes for the both instructions

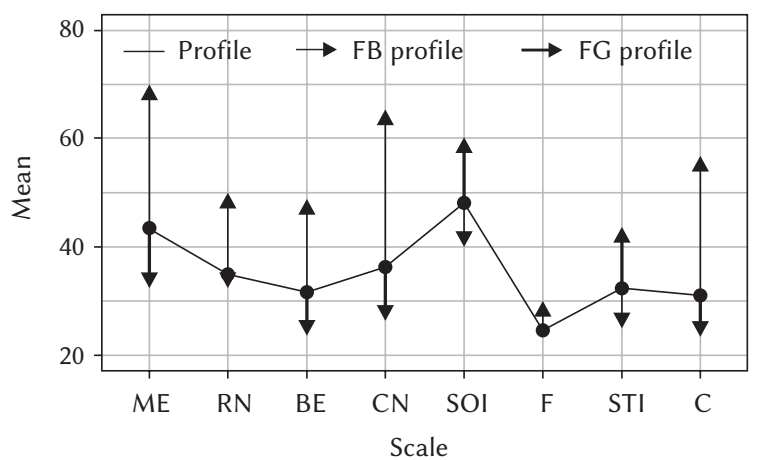

True profile for people from cluster FG2 and changes for the both instructions

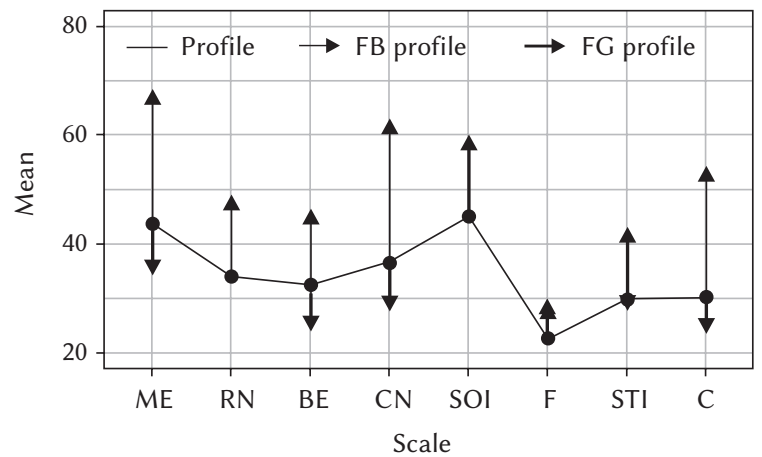

True profile for people from cluster FG3 and changes for the both instructions

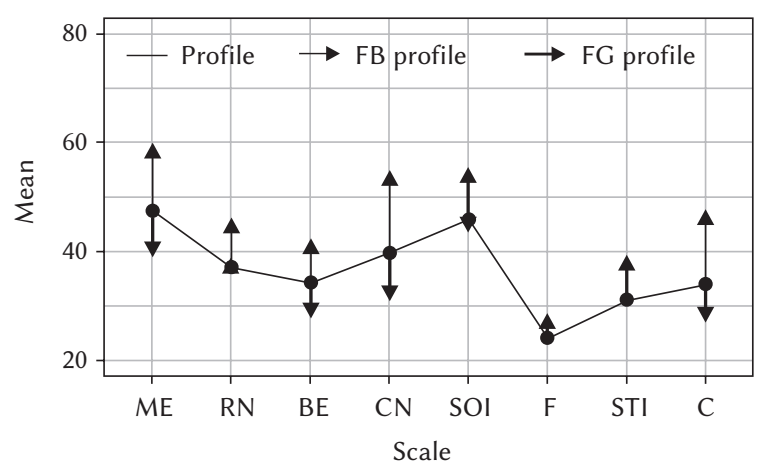

True profile for people from cluster FG4 and changes for the both instructions

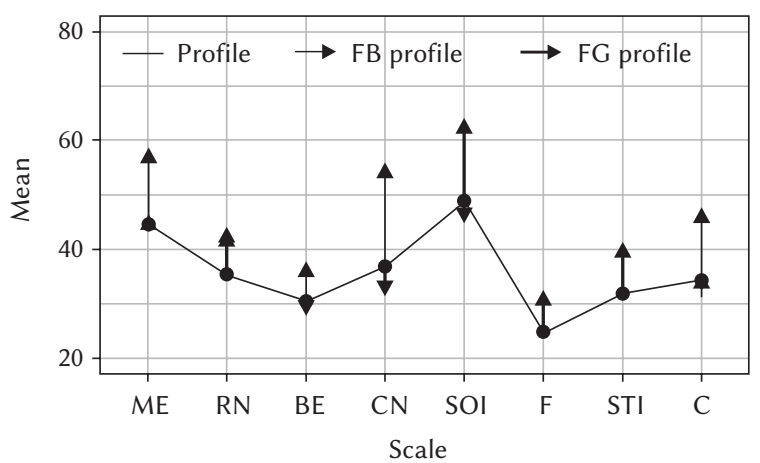

True profile for people from cluster FG5 and changes for the both instructions

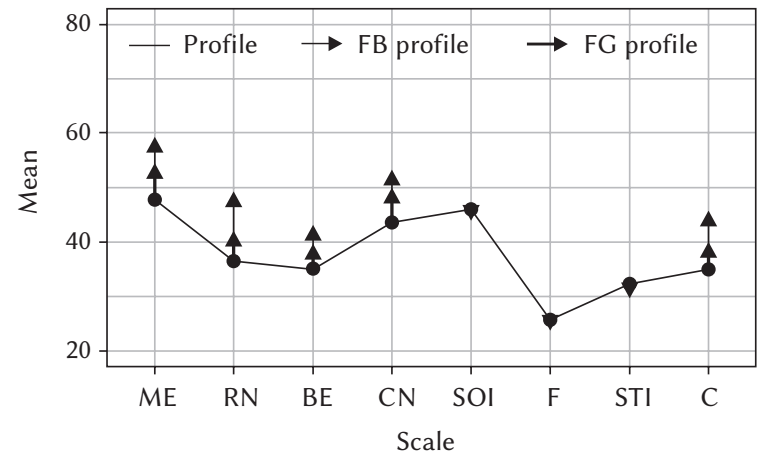

True profile for people from cluster FB1 and changes for the both instructions

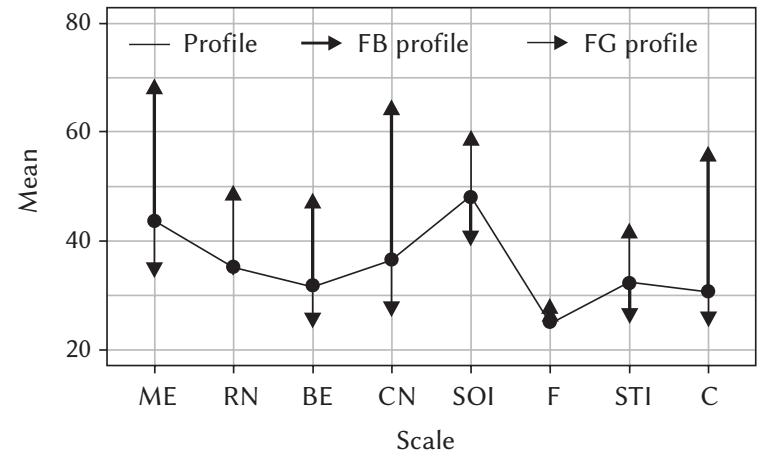

True profile for people from cluster FB2 and changes for the both instructions

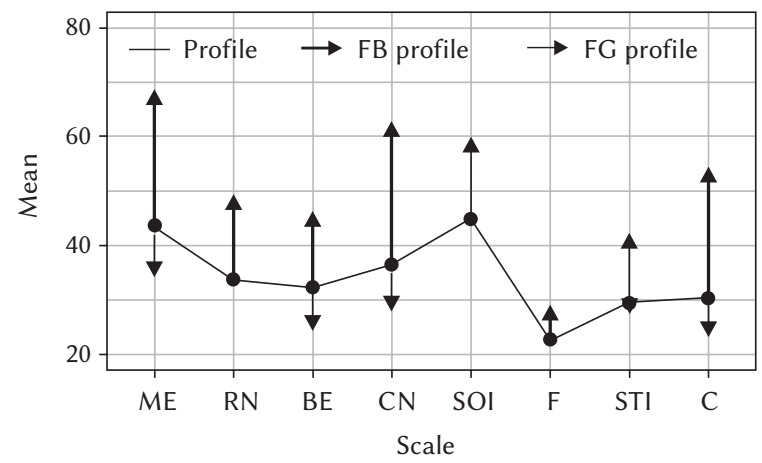

True profile for people from cluster FB3 and changes for the both instructions

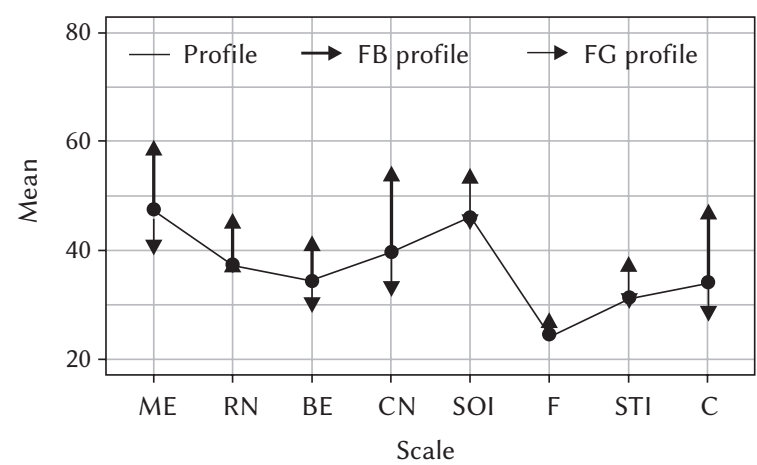

Note. ME - Machiavellian egocentricity; RN - rebellious nonconformity; BE - blame externalization; $\mathrm{CN}$ - carefree nonplanfulness; SOI - social influence; F - fearlessness; STI - stress immunity; C - coldheartedness; FG1, 2, 3, 4 - faking good, cluster 1, 2, 3, 4, 5 ; FB1, 2, 3 - faking bad, cluster 1, 2, 3 .

Figure 2. The figures show how the participants traits (continuous profile) were changed as a result of fakinggood and faking-bad instructions. The thick arrows indicate the profile corresponding to the faking-good instruction and the thin ones indicate the average profile of the same individuals for the opposite instruction. The sizes of the groups are: $n=68,40,20,24,21,87,38$, and 48 , respectively. 
chopathy. This approach to the obtained results suggests that individuals with the highest levels of psychopathy dimensions do not exhibit a tendency to develop a distinct strategy of presenting themselves in a worse light.

\section{FAKING GOOD}

We identified the relationships between the profiles distinguished based on cluster analysis of self-presentations suggesting better adjustment (faking good), the "honest" profiles (subjectively true characteristics), and the ways of forming the image of simulation (faking bad) typical of the participants making up these clusters (Figure 2).

FG1. The participants from this cluster faked better social adjustment by decreasing the scores on most scales making up the Self-centered impulsivity factor $(\mathrm{ME}, \mathrm{BE}$, and $\mathrm{CN}$ - the unchanged $\mathrm{RN}$ score was the exception) and decreasing the presented level of Coldheartedness $(\mathrm{C})$, while at the same time increasing the scores on the scales making up the Fearless dominance factor (SOI, F, STI).

Compared to the self-image they subjectively regarded as true, the participants from cluster FG1 presented themselves as less narcissistic and cynical, less prepared to bend the rules for their purposes and less prepared to take advantage of others, less inclined to blame other people for their failures, less carefree and indifferent regarding the consequences of their actions, as well as less cold-hearted, less disloyal, and less devoid of concern and compassion. What they saw as advisable was to present themselves as more charming and capable of influencing others, self-confident, and free of social anxiety as well as anxiety stemming from the anticipation of physical threats. They presented themselves as brave people capable of acting under pressure and maintaining composure in difficult circumstances.

The group of participants making up cluster FG1 produced an impression of worse adjustment (faking bad) by increasing the scores on Self-centered impulsivity scales (ME, RN, BE, CN) and on most scales of the Fearless dominance factor (SOI, F, STI).

FG2. The participants in this cluster faked better social adjustment in a similar way as participants from cluster FG1, but the point of departure was different - scores on the Fearless dominance factor scales were lower and increased to a greater degree than in cluster FG1.

The participants from cluster FG2 - like those from cluster FG1 - presented themselves as less narcissistic and cynical, less ready to bend the rules for their purposes and abuse others, less ready to blame others for their own failures, less carefree or indifferent regarding the consequences of their actions, as well as less cold-hearted, less disloyal, or less devoid of concern and sympathy. Similarly to individuals from cluster FG1, when producing a false impression of themselves, they decreased their tendency to defy authorities and disregard social norms as well as to get bored. The trait they regarded as socially valuable was resistance to stress, fear-inducing events, and difficult circumstances.

The impression of worse adjustment (faking bad) in this group was obtained by increasing the scores on Self-centered impulsivity scales (ME, RN, BE, CN) and on Coldheartedness $(\mathrm{C})$. When distorting their image, these people did not use the scales of the Fearless dominance factor (SOI, F, STI).

FG3. As a result of faking good, the participants from this cluster created a profile with an image that was average compared to the remaining clusters.

The individuals producing this (positive) impression departed from their honest profile only to a small extent: the level of traits making up the Self-centered impulsivity factor (except RN) slightly decreased. To a small extent, they also made use of the social value of items making up the Coldheartedness scale (C). In the case of these individuals, modification in the impression of better adjustment consisted in an increase in the scores on some scales of the Fearless dominance factor: perceived ability to influence and manipulate others, making an impression, and freedom from social anxiety (SOI) as well as resistance to stress and the ability to maintain composure under pressure or in the face of difficult circumstances and anxiety-inducing stimuli (STI).

The impression of worse adjustment (faking bad) in this group was produced by increasing the scores on Self-centered impulsivity scales (ME, RN, BE, CN) and the trait of Coldheartedness $(\mathrm{C})$. When distorting the image of themselves, individuals from this cluster did not use the Fearless dominance scales (SOI, F, STI).

FG4. When distorting their profile towards better adjustment (faking good), the participants making up cluster FG4 used the items of Self-centered impulsivity scales: they increased the IN score and slightly decreased the level of $\mathrm{CN}$ (the levels of ME and BE remained unchanged). These individuals did not change the level of Coldheartedness (C). When distorting their image, they increased the scores on Fearless dominance scales (SOI, F, STI).

The participants from this cluster decided that they would present themselves as better by enhancing their fearlessness, audacity, defiance of authorities, and disregard of social norms. They presented themselves as "rebels without a cause", not careless and nonchalantly imprudent but rather aware of their ability to influence and manipulate others, self-confident, as well as free of social anxiety and anxiety involving the anticipation of physical danger. What they regarded as desirable was resistance to stress and the ability to maintain composure in the face of tensions and anxiety-inducing stimuli. 
The impression of worse adjustment (faking bad) was obtained by increasing the scores on Self-centered impulsivity scales ( $\mathrm{ME}, \mathrm{RN}, \mathrm{BE}, \mathrm{CN})$ and on Coldheartedness (C). The scores on the scales of Fearless dominance (SOI, F, STI) remained unchanged.

FG5. The participants making up cluster FG5 (distinguished based on faking good) exhibited the greatest difficulty in presenting themselves as individuals whose social functioning is better. These participants were unable to use the social potential of the majority of items in the test, which were part of all scales of the Fearless dominance and Coldheartedness factors, as well as ME and BE. The change towards better adjustment was restricted to a small modification in RN and $\mathrm{CN}$ scores.

The group of participants making up cluster FG5 produced an impression of worse adjustment (faking bad) by increasing the scores on the scales of Self-Centered Impulsivity (ME, RN, BE, CN) and the level of Coldheartedness; the magnitude of change was considerably lower than in the remaining clusters. The participants' modification of the image of themselves did not involve changes in the scores on Fearless Dominance scales (SOI, F, STI).

We found no clear differences between the profiles of intentional faking exhibited by participants representing clusters FG1, FG2, FG3, and FG4. However, the profiles of these groups differ from the "honest" profile of individuals making up cluster FG5. This profile is characterized by the highest scores on scales included in the factors of Self-centered impulsiveness (ME, RN, BE, CN) and Coldheartedness (C), with the highest score on Fearlessness (F) and with the lowest scores on Social influence (SOI) and Stress immunity (STI). It can be tentatively concluded that the kind of faking good exemplified by participants from FG5 is the most representative of individuals with an increased level of psychopathic traits.

\section{FAKING BAD}

Cluster analysis performed for participants distinguished based on the character of the profile resulting from faking worse adjustment revealed the existence of three ways of faking bad.

FB1. The participants making up cluster FB1 produced an image of worse adjustment by clearly increasing the levels of traits constituting the factors of Self-Centered impulsivity (ME, RN, BE, CN) and Coldheartedness (C). At the same time, they decreased the scores on two scales of the Fearless dominance (FD) factor (there was no change in the level of F).

The participants producing pictures distorted towards better social adjustment (faking good) tended to lower the level of Self-centered impulsivity (ME, BE, $\mathrm{CN}$; no change in the level of RN) and Coldhearted- ness (C). By contrast, scores on the Fearless dominance scales (SOI, F, STI) were increased.

FB2. In the case of participants making up this cluster, an image of worse adjustment (faking bad) was obtained by increasing the scores on all dimensions except Stress immunity (STI), which remained unmodified. The extent of these modifications was significantly higher in the case of most scales than the extent of faking performed by the participants making up cluster FB1.

These individuals produced an impression of better adjustment by lowering the levels of Selfcentered impulsivity (ME, BE, CN, RN) and Coldheartedness (C). In contrast, the scores on the scales of Fearless dominance (SOI, STI) were increased, with the score on the F scale remaining unmodified.

The participants from clusters FB1 and FB2 faked the results to produce an image of worse adjustment, presenting themselves as individuals perceiving themselves as better than others, narcissistic, cynical and ruthless in relations with others, prepared to manipulate and lie for egoistic purposes. They stressed their nonconformism, defiance of authorities, and audacious disregard of social norms. They showed that they saw the world as hostile and full of evil intentions, blaming it for their problems and failures, increasing the tendency to blame others as well as to rationalize their own antisocial and asocial behavior. They presented themselves as unconventional individuals, easily bored and therefore incapable of planning their activities and pursuing long-term goals, acting without premeditation and without considering alternative ways of solving problems, imprudent and refusing to learn from their own mistakes. The participants clearly produced an impression of coldheartedness, lack of empathy, and inability to sympathize with other people's suffering, as well as lacking a sense of guilt, concern, loyalty, and lasting bonds with other people.

Intergroup differences manifested themselves in the use of characteristics referred to as fearless dominance when faking bad. The participants making up cluster FB2 presented themselves as individuals with a sense of having high abilities to manipulate and influence others, believing themselves to be eloquent, making a good first impression, self-confident, and free of social anxiety. Individuals from cluster FB1 decided that what contributed to the negative self-presentation was the lowering of the level of their own presented traits compared to the image of themselves subjectively perceived as subjectively true. At the same time, they presented themselves as less resistant to stress (compared to that image) and less capable of maintaining composure in difficult circumstances. The participants from cluster FB2 did not use the potential of items relating to stress immunity. They did use items relating to readiness to engage in risky behaviors, lack of anticipatory 
anxiety concerning physical threats, and presenting themselves as fearless.

It should be added that individuals from cluster FB2 presented an image with a higher level of the above traits (the exception being the Blame externalization (BE) and Carefree nonplanfulness (CN) scales).

FB3. The participants making up cluster FB3 were hardly able to intentionally fake the results of the study in the case of instructions inducing simulation as well as dissimulation.

Slight modifications (such as the increase in the $\mathrm{RN}$ score in the attempt to produce a negative image) show that these people were unable to use the social potential of the items to present themselves in a way diverging from the subjective truth.

\section{DISCUSSION}

According to the results of the present study, the VR and DR scales make it possible to detect faking that consists in using the potential of items making up the Self-centered impulsivity factor: we found correlations between VR scores and faking good and between DR scores and faking bad.

We distinguished five separate patterns of faking good and three patterns of faking bad during selfreport assessment. It can be tentatively concluded that the levels of traits and behavior patterns defining psychopathic personality are related to a particular profile produced as a result of faking good. The profile of this group of participants is characterized by an increased level of all dimensions of Self-centered Impulsivity (ME, RN, BE, CN) and Coldheartedness (C) compared to the remaining groups, accompanied by the lowest level of Social influence (SOI).

The results of the preliminary studies presented in this article show observable patterns of intentional faking in the questionnaire-based method of personality assessment, which refers to the description of personality traits and patterns of behavior typical of psychopathic individuals. Thus, the present research can contribute to the discussion on the validity of self-report methods in the case of individuals with a higher level of psychopathic traits.

Clinical observations of psychopaths suggest that they have both high ability and a tendency to deceive and manipulate in relationships (Cooke et al., 2007; Hare, 2003; Rogers \& Cruise, 2000). According to the opponents of the use of self-report methods, in the case of a questionnaire study there is a high probability of expressing both components of the models explaining the process of intentional faking, i.e. motivation and perceived ability (McFarland \& Ryan, $2000,2006)$. These researchers point to the instrumental motives in interpersonal relations, as well as to satisfaction and pride in the ability to use cognitive empathy to deceive others typical of psychopaths.
On the basis of the analysis of patterns of faking good, a group of people characterized by a higher level of psychopathic traits was distinguished. According to the obtained results, these people have a particular difficulty in presenting themselves as better adjusted. These results are difficult to compare with the inconclusive results of a few studies on faking good (e.g., Book et al., 2006; MacNeil \& Holden, 2006), which were focused on investigating the correlation of the phenomenon of effective and ineffective faking good with the total result of psychopathy, or isolated dimensions of psychopathy. However, it is worth mentioning that these researchers suggested that psychopathic individuals can decrease their psychopathy scores to a greater extent than people with low psychopathy. The results of the research presented in this article indicate that the group of people with increased features of psychopathy had greater difficulties than the other participants in presenting a false self-image different from the one presented as sincere. Perhaps these differences are explained by the fact that the participants in the compared studies were characterized by a different configuration of respective dimensions of psychopathy. In other words, they were psychopathic due to a different configuration of features.

Previous studies on the phenomenon of faking bad in the self-report personality measures prove that it is irrelevant to the features of psychopathy (e.g., Book et al., 2006; Edens et al., 2000; MacNeil \& Holden, 2006). Also in these studies, no relationship was identified between psychopathy and a separate faking bad strategy. Analysis of patterns of negative self-image (faking bad) did not show any group differences in the features and patterns of behavior that make up psychopathy. Nevertheless, it was found that people who were included in the cluster with the highest inability to fake good, i.e. persons with the highest intensity of psychopathic traits, also had great difficulty in creating a negative self-image. Interestingly, they tried to present themselves in a worse light by increasing the results of the same scales, which in this cluster were also increased when the respondents answered "honestly". Of course, it is possible that the participants in this cluster were not so much incapable of creating an image different from the "honest" image, as incapable of creating an image different from the one that was intentionally or unintentionally distorted and presented as "honest".

Assuming, however, that the honest result was a valid one, the results of this study may strengthen the position of the researchers who advocate the use of questionnaire methods in the assessment of psychopathy. According to this perspective, it can be assumed that despite the high ability to manipulate and to manage the self-image, in the case of a questionnaire-based assessment in which there is 
no possibility to be tuned in to the other person's reactions and expectations, the ability of the psychopath to present a false self-image is limited. In other words, the Machiavellian abilities of psychopaths reveal themselves in the process of deception rather than faking.

\section{LIMITATIONS AND FUTURE DIRECTIONS FOR RESEARCH}

In the study we assumed that the image obtained in self-report was true, whereas in fact even the image referred to as honest was only subjectively true and subject to unintentional distortions - for example, defensive distortions or ones that gave a sense of integrity. Further study should explore the possibilities of controlling these distortions and identifying their personality determinants. Another interesting area for further analyses seems to be the relationship between the configuration of psychopathic traits and the profiles of faking.

A limitation of our results and an area of future analysis may be the use of latent profile analysis (LPA) with covariates instead of cluster analysis. Although the results of both methods and the results obtained by us were convergent (for FB they were identical, for FG similar), it should be considered to include variables correlated with the studied phenomenon of faking good or bad in the analysis.

\section{ENDNOTES}

1 Two categories of response bias have been distinguished: response style - i.e., a permanent attitude, independent of the questionnaire - and response set - a temporary attitude stemming from a particular motive or disturbance (Paulhus, 2002, p. 49).

\section{RefERENCES}

American Psychiatric Association (2000). Diagnostic and statistical manual of mental disorders ( $4^{\text {th }}$ ed., text rev.). Washington: American Psychiatric Association.

Arendasy, M., Sommer, M., Herle, M., Schützhofer, B., \& Inwanschitz, D. (2011). Modeling effects of faking on objective personality test. Journal of Individual Differences, 32, 210-218.

Book, A. S., Holden, R. R., Starzyk, K. B., Wasylkiw, L., \& Edwards, M. J. (2006). Psychopathic traits and experimentally induced deception in self-report assessment. Personality and Individual Differences, 41, 601-608.

Brzezińska, A. I., \& Brzeziński, J. M. (2011). Skale szacunkowe w badaniach diagnostycznych [Rating scales in diagnostic studies]. In J. M. Brzeziński (Ed.), Metodologia badań spotecznych. Wybór tekstów [The methodology of social studies] (pp. 299399). Poznań: Zysk i S-ka.

Cleckley, H. (1988). The mask of sanity. An attempt to clarify some issues about the so-called psychopathic personality. St. Louis: C. V. Mosby.

Cooke, D. J., Michie, C., \& Skeem, J. (2007). Understanding the structure of the Psychopathy Checklist-Revised. An exploration of methodological confusion. British Journal of Psychiatry, 190, 39-50.

Duda, R. O., \& Hart, P. E. (1973). Pattern Classification and Scene Analysis. New York: Wiley.

Edens, J. F., Buffington, J. K., \& Tomicic, T. L. (2000). An investigation of the relationship between psychopathic personality traits and malingering on the Psychopathic Personality Inventory. Assessment, 7, 281-296.

Edens, J.F., Buffington, J.K., Tomicic, T.L., \& Riley, B.D. (2001). Effects of Positive Impression Management on the Psychopathic Personality Inventory. Law and Human Behavior, 25, 3, 235-256.

Eitan, D. G. (2011). Is the truth visible? Study along the L scale. Open Psychology Journal, 4, 73-87.

Furnham, A. (1986). Response bias, social desirability and dissimulation. Personality and Individual Differences, 7, 385-400.

Furnham, A. (1990). Faking personality questionnaires: Fabricating different profiles for different purposes. Current Psychology: Research \& Reviews, 9, 46-55.

Gacono, C. B., Meloy, J. R., Sheppard, K., Speth, E. B., \& Roske, A. (1995). A clinical investigation of malingering and psychopathy in hospitalized insanity acquittees. Bulletin of the American Academy of Psychiatry and the Law, 23, 1-11.

Goffin, R. D., \& Boyd, A. C. (2009). Faking and personality assessment in personnel selection: Advancing models of faking. Canadian Psychology, 50, 151-160.

Goffin, R. D., \& Christiansen, N. D. (2003). Correcting personality tests for faking: A review of popular personality tests and initial survey of researchers. International Journal of Selection and Assessment, 11, 340-344.

Groth, J., \& Cierpiałkowska, L. (2012). Pięcioczynnikowy model osobowości a profile psychopatii w grupie nieprzestępczej [The five-factor model of personality and psychopathy profiles in the noncriminal group]. Czasopismo Psychologiczne, 18, 107-118.

Hare, R. D. (1996). Psychopathy: A clinical construct whose time has come. Criminal Justice and Behavior, 23, 25-54.

Hare, R. D. (2003). Hare PCL-R ( $2^{\text {nd }}$ ed.). Toronto: Multi-Health Systems.

Hare, R. D. (2006). Psychopaci sq wśród nas [Psychopaths are among us]. Kraków: Wydawnictwo Znak. 
Hare, R. D. (2008). Psychological instruments in the assessment of psychopathy. In A. Felthous \& H. Sass (Eds.), The international handbook of psychopathic disorders and the law (pp. 41-67). Chichester: John Wiley and Sons, Ltd.

Hare, R. D., Harpur, T. J., Hakstian, A. R., Forth, A. E., Hart, S. D., \& Newman, J. P. (1990). The revised psychopathy checklist: Reliability and factor structure. Psychological Assessment, 25, 338-341.

Hare, R. D., \& Neumann, C. S. (2006). The PCL-R assessment of psychopathy. Development, structural properties, and new directions. In C. J. Patrick (Ed.), Handbook of psychopathy (pp. 58-88). New York: The Guilford Press.

Jackson, D. N., \& Wroblewski, V. R. (2000). The impact of faking on employment tests: Does forced choice offer a solution? Human Performance, 13, 371-388.

Klaver, J. R., Lee, Z., \& Hart, S. D. (2007). Psychopathy and nonverbal indicators of deception in offenders. Law and Human Behavior, 31, 337-351.

Kosson, D. S., Gacono, C. B., \& Bodholdt, R. H. (2000). Assessing psychopathy: Interpersonal aspects and clinical interviewing. In C. B. Gacono (Ed.), The clinical and forensic assessment of psychopathy: A practitioner's guide (pp. 203-230). Mahwah: Lawrence Erlbaum Associates.

Lilienfeld, S. O. (1998). Methodological advances and developments in the assessment of psychopathy. Behaviour Research and Therapy, 36, 99-125.

Lilienfeld, S. O., \& Fowler, K. A. (2006). The self-report assessment of psychopathy. In Ch. J. Patrick (Ed.), Handbook of psychopathy (pp. 107-132). New York: The Guilford Press.

Lilienfeld, S. O., \& Widows, M. R. (2005). Psychopathic Personality Inventory-Revised. Professional manual. Lutz: Psychological Assessment Resources, Inc.

Lynam, D. R. (2002). Psychopathy from the perspective of the five-factor model of personality. In P. T. Costa \& T. A. Widiger (Eds.), Personality disorders and the five-factor model of personality ( $p p$. 325-348). Washington: American Psychological Association.

Lynam, D. R., \& Derefinko, K. J. (2006). Psychopaty and personality. In C. J. Patrick (Ed.), Handbook of psychopathy (pp. 133-155). New York: The Guilford Press.

MacNeil, B. M., \& Holden, R. R. (2006). Psychopathy and the detection of faking on self-report inventories of personality. Personality and Individual Differences, 41, 641-651.

McFarland, L. A., \& Ryan, A. M. (2000). Variance in faking across noncognitive measures. Journal of Applied Psychology, 85, 812-821.

McFarland, L. A., \& Ryan, A. M. (2006). Toward an integrated model of applicant faking behavior. Journal of Applied Social Psychology, 36, 979-1016.
Meloy, J. R., \& Gacono, C. B. (2000). Assessing psychopathy: Psychological testing and report writing. In C. B. Gacono (Ed.), The clinical and forensic assessment of psychopathy: A practitioner's guide (pp. 231-250). Mahwah: Lawrence Erlbaum Associates.

Miller, J.D., Lynam, D.R., Widiger, T.A., \& Leukefeld, C. (2001). Personality disorders as extreme variants of common personality dimensions: Can the FiveFactor Model adequately represent psychopathy? Journal of Personality, 69, 253-276.

Mullins-Sweatt, S. N., \& Widiger, T. A. (2006). The five-factor model of personality disorder. In R. F. Krueger \& J. L. Tackett (Eds.), Personality and psychopathology (pp. 39-70). New York: The Guilford Press.

Neumann, C. S., Malterer, M. B., \& Newman, J. P. (2008). Factor structure of the Psychopathic Personality Inventory (PPI): Findings from a large incarcerated sample. Psychological Assessment, 20, 169-174.

Paluchowski, W. J. (2001). Diagnoza psychologiczna [Psychological assessment]. Warszawa: Scholar.

Paulhus, D. L. (1984). Two-component models of socially desirable responding. Journal of Personality and Social Psychology, 46, 598-609.

Paulhus, D. L. (1998). Interpersonal and intrapsychic adaptiveness of trait self-enhancement: A mixed blessing? Journal of Personality and Social Psychology, 74, 1197-1208.

Paulhus, D. L. (2002). Socially desirable responding: The evolution of a construct. In H. I. Braun, D. N. Jackson, \& D. E. Wiley (Eds.), The role of constructs in psychological and educational measurement (pp. 49-69). Mahwah: Lawrence Erlbaum Publishers.

Paulhus, D. L., \& Reid, D. (1991). Enhancement and denial in socially desirable responding. Journal of Personality and Social Psychology, 60, 307-317.

Paulhus, D. L., \& Holden, R. R. (2009). Measuring self-enhancement: From self-report to concrete behavior. In C. R. Agnew, D. E. Carlston, W. G. Graziano, \& J. R. Kelly (Eds.), Then a miracle occurs: Focusing on behavior in social psychological theory and research (pp. 221-240). New York: Oxford University Press.

R Core Team (2017). R: A language and environment for statistical computing. R Foundation for Statistical Computing, Vienna, Austria. Retrieved from https://www.R-project.org

Reise, S. P., \& Oliver, C. J. (1994). Development of a California Q-set indicator of primary psychopathy. Journal of Personality Assessment, 62, 130-144.

Reynolds, A., Richards, G., de la Iglesia, B., \& Rayward-Smith, V. (1992). Clustering rules: A comparison of partitioning and hierarchical clustering algorithms. Journal of Mathematical Modelling and Algorithms, 5, 475-504. doi: http://dx.doi. org/10.1007/s10852-005-9022-1. 
Rogers, R., \& Cruise, K. R. (2000). Malingering and deception among psychopaths. In C. B. Gacono (Ed.), The clinical and forensic assessment of psychopathy: A practitioner's guide (pp. 269-284). Mahwah: Lawrence Erlbaum Associates.

Sanocki, W. (1970). Postawa wobec badania a wyniki inwentarza osobowości [Attitude towards the study and personality inventory scores]. Przeglad Penitencjarny, 27, 49-72.

Sanocki, W. (1978). Kwestionariusze osobowości w psychologii [Personality questionnaires in psychology]. Warszawa: Wydawnictwo Naukowe PWN.

Seto, M. C., Khattar, N. A., Lalumiére, M. L., \& Quinsey, V. L. (1997). Deception and sexual strategy in psychopathy. Personality and Individual Differences, 22, 301-307.

Siuta, J. (2006). Inwentarz Osobowości NEO-PI-R Paula T. Costy Jr i Roberta R. McCrae [The NEO-PI-R Personality Inventory by Paul T. Costa Jr. and Robert R. McCrae. Polish adaptation: A manual]. Warszawa: Pracownia Testów Psychologicznych Polskiego Towarzystwa Psychologicznego.

Snell, A. F., Sydell, E. J., \& Lueke, S. B. (1999). Towards a theory of applicant faking: Integrating studies of deception. Human Resource Management Review, 9, 219-242.

Widiger, T. A., \& Lynam, D. R. (2003). Psychopathy and the five-factor model of personality. In Th. Millon, E. Simonsen, M. Birket-Smith, \& R. D. Davis (Eds.), Psychopathy. Antisocial, criminal, and violent behavior (pp. 171-187). New York: The Guilford Press.

Witt, E. A., Donnellan, M. B., \& Blonigen, D. M. (2009). Using existing self-report inventories to measure the psychopathic personality traits of fearless dominance and impulsive antisociality. Journal of Research in Personality, 43, 1006-1016.

Zickar, M. J., \& Robie, C. (1999). Modeling faking good on personality items: An item-level analysis. Journal of Applied Psychology, 84, 551-563. 